\title{
Effect of steam pretreatment on oil palm empty fruit bunch for the production of sugars
}

\begin{abstract}
Lignocellulose into fuel ethanol is the most feasible conversion route strategy in terms of sustainability. Oil palm empty fruit bunch (EFB) generated from palm oil production is a huge source of cellulosic material and represents a cheap renewable feedstock which awaits further commercial exploitation. The purpose of this study was to investigate the feasibility of using steam at $0.28 \mathrm{MPa}$ and $140{ }^{\circ} \mathrm{C}$ generated from the palm oil mill boiler as a pretreatment to enhance the digestibility of EFB for sugars production. The effects of steam pretreatment or autohydrolysis on chemical composition changes, polysaccharide conversion, sugar production and morphology alterations of four different types of EFB namely fresh EFB (EFB1), sterilized EFB (EFB2), shredded EFB (EFB3) and ground EFB (EFB4) were evaluated. In this study, the effects of steam pretreatment showed major alterations in the morphology of EFB as observed under the scanning electron microscope. Steam pretreated EFB2 was found to have the highest total conversion of $30 \%$ to sugars with $209 \mathrm{~g} \mathrm{~kg}-1 \mathrm{EFB}$. This production was 10.5 fold higher than for EFB1 and 1.6 fold and 1.7 fold higher than EFB3 and EFB4, respectively. The results suggested that pretreatment of EFB by autohydrolysis using steam from the mill boiler could be considered as being a suitable pretreatment process for the production of sugars. These sugars can be utilized as potential substrates for the production of various products such as fuel ethanol.
\end{abstract}

Keyword: Steam pretreatment; Autohydrolysis; Oil palm empty fruit bunch; Elaeis guineensis; Ethanol 